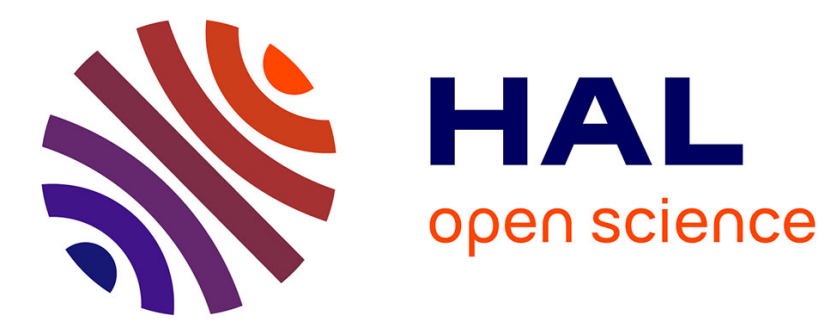

\title{
A Grid Connected PV System Fault Diagnosis Method
} Nikolaos Sapountzoglou, Bertrand Raison

\section{To cite this version:}

Nikolaos Sapountzoglou, Bertrand Raison. A Grid Connected PV System Fault Diagnosis Method. 20th IEEE International Conference on Industrial Technology 2019, Feb 2019, Melbourne, Australia. 10.1109/ICIT.2019.8755166 . hal-02072272

\section{HAL Id: hal-02072272 https://hal.science/hal-02072272}

Submitted on 17 Jul 2019

HAL is a multi-disciplinary open access archive for the deposit and dissemination of scientific research documents, whether they are published or not. The documents may come from teaching and research institutions in France or abroad, or from public or private research centers.
L'archive ouverte pluridisciplinaire HAL, est destinée au dépôt et à la diffusion de documents scientifiques de niveau recherche, publiés ou non, émanant des établissements d'enseignement et de recherche français ou étrangers, des laboratoires publics ou privés. 


\section{A Grid Connected PV System Fault Diagnosis Method}

\author{
Nikolaos Sapountzoglou \\ Univ. Grenoble Alpes, CNRS, Grenoble INP, G2Elab \\ 38000 Grenobe, France \\ nikolaos.sapountzoglou@g2elab.grenoble-inp.fr
}

\author{
Bertrand Raison \\ Univ. Grenoble Alpes, CNRS, Grenoble INP, G2Elab \\ 38000 Grenobe, France \\ bertrand.raison@g2elab.grenoble-inp.fr
}

\begin{abstract}
In this paper, a fault diagnosis method for gridconnected photovoltaic (GCPV) systems is presented. The method is based on the monitoring of the ac electrical variables and especially on the measurements of the currents and voltages at the output of the inverter. After a short introduction on the topic, the necessary steps to build a GCPV system model are described; the photovoltaic (PV) array is connected to the grid through a boost converter and an inverter. Four categories of faults were studied: a) faults inside the PV array, b) faults between the dc bus and the ground, c) faults in the power electronics devices and d) faults in the grid. The response of the system to each fault case was then observed, leading to the generation of a set of symptoms and the creation of the fault signature table. Using this fault signature table, a fault diagnosis method was developed. This latter is able to detect all the studied faults and localize sixteen out of the total of twenty fault cases; two groups of faults and fourteen individual fault cases. Finally, it creates an alarm signal in less than $60 \mathrm{~ms}$, assuming that only one fault is occurring at a time. The robustness of the method was validated for different irradiance levels by simulation means.
\end{abstract}

\section{INTRODUCTION}

Grid-connected photovoltaics is a remarkably growing sector and the second most popular among the renewable energy sources behind wind farms. In 2016 alone, the global PV installed capacity increased by $76 \mathrm{GW}$ reaching a total of $303 G W$ which represents the $1.6 \%$ of the global energy demand and the $33 \%$ of the total installed capacity of renewable energy sources [1]. More specifically, for the International Energy Agency (IEA) countries GCPV systems account for $99.55 \%$ of the total installed PV capacity. In order to optimize their performance, increase their reliability and reduce their maintenance cost, several fault detection approaches for GCPVs have been explored over the last years [2]-[16].

Among the numerous fault detection and diagnosis approaches, five big categories can be distinguished: tracing of $I-V$ curves, development of predictive models, statistical analysis of measurements, artificial intelligence methods and signal analysis. The most popular of those approaches are cited below.

A classical fault detection technique based on the tracing of module $I-V$ curves [2], detects and locates accurately the faulty modules. A different curve based method is presented

This project has received funding from the European Union's Horizon 2020 research and innovation programme under the Marie Skłodowska-Curie grant agreement No 675318 (INCITE) in [3] where instead of the $I-V$ curve, the $(-d I / d V)-V$ curve is traced.

Another set of tools for fault detection are the comparisons between measured and simulation expected current, voltage and power values. Such comparisons were used in fault detection algorithms described in [4] and [5]. A site specific and low complexity detection system was build around a threesigma $(3 \sigma)$ rule for the standard deviation of the measured over modeled ac power ratio [6]. Moreover, a diagnostic procedure based on the absolute performance ratio error (APRE) was developed in [7].

The statistical approach of fault detection for GCPV is also quite popular. Two parallel fault detection algorithms based on a statistical approach were implemented in [8], one for detecting faults on the dc side and one on the ac side of the GCPV plant. Another statistical method [9], relies on the use of an exponentially weighted moving average control (EWMA) chart based on the residuals of the dc output power, voltage and current, in order to detect and identify short circuit (SC), open circuit (OC) and partial shading faults in the PV array. In addition to the above methods, a decision tree model with remarkable fault detection and classification accuracy is proposed in [10].

Other researchers used artificial intelligence (AI) methods such as neural networks [11] to detect PV module-level faults and fuzzy logic systems [12] capable of dealing with noisy data.

While some methods can provide supervision solutions through satellite data where the on-site measurements of the solar irradiance are replaced by satellite data [13], other methods such as time domain reflectometry (TDR) [14], are independent of solar irradiance changes. TDR was used to detect faulty strings through signal delays and changes in the waveform of the applied into the string voltage signal. Futhermore, a frequency spectrum analysis of the studied signals was used in [15] in order to detect component faults inside the inverter. Finally, the wavelet transform was introduced in [16] in order to detect rapid changes in signals that Fourier transform can not.

Besides their accuracy, some methods are very costly [10], [13] while others study only a limited number of faults [4], [5], [7], [9]-[11], [13], [16]. Special attention must be also paid on the use of learning methods [11], [12] where the risk 
of not identifying a fault in case its data are different from the training data set is significant. So far, no research has been found that monitored the GCPV as a complete system; each one of them is concentrated on a specific part of the GCPV in order to detect faults. Additionally, up to now, no study has focused on the possibility of detecting and isolating faults on both the dc and the ac side with measurements taken only from the ac side. Such a possibility would significantly reduce the number of sensors required for the supervision of the system and thus the total system cost.

In this paper, the signal approach was selected to develop a fault diagnosis method for GCPV systems based on current and voltage measurements at the output of the inverter, examining faults occurring on both the dc and the ac side of the plant. A two-stage conversion topology of the GCPV was used to connect the PV array to the grid through a boost converter and an inverter; a three phase connection was selected for the connection of the inverter to the grid. The following fault cases were considered: faults inside the PV array, faults on the dc bus, faults in the converter and inverter and faults in the grid. The response of the system to the studied faults was observed and a list of symptoms was generated accordingly. An algorithm was then developed and validated for different irradiance levels. The algorithm is able to detect and isolate faults or group of faults in less than $60 \mathrm{~ms}$.

This paper is divided in the following sections: the next Section gives a brief description of the developed GCPV system model and its characteristics. The third Section presents the list of the studied fault cases and a step-by-step process that leads to the creation of the fault signature table. The fourth Section analyzes the fault diagnosis method based on the fault signature table. Finally, the conclusions and some future work proposals are summarized in the final Section.

\section{MODELING OF GCPV SYSTEMS FOR FAULT DETECTION}

The modeling of a GCPV system can be decomposed into three simple steps. First of all, the use of the mathematical equations of the PV cell's equivalent circuit is necessary for the the extraction of the characteristic parameters; the calculations at this stage are subject to the limited available data provided by the manufacturer's data sheets [17]. After the extraction of the parameters and based on their values, follows the solution of the transcendental current-voltage characteristic equation [18]. The last step is the design of the PV array by connecting in series and in parallel all the necessary elements.

\section{A. PV Cell: Bishop's model}

An alternative to the widely used one-diode model and a more appropriate one for fault detection simulations, is the Bishop's model [19]. It consists of an upgraded version of the one-diode model. The additional element connected in series with the shunt resistance is a non-linear multiplication factor. In that way, the Bishop's model takes into account the avalanche effect of the diode thus permitting the monitoring of the cell's response in the three quadrants - the first (I), the second (II) and the fourth (IV) - of the $I-V$ characteristic curve as presented in Fig. 1a. Its equivalent electrical circuit is given in Fig. 1b.

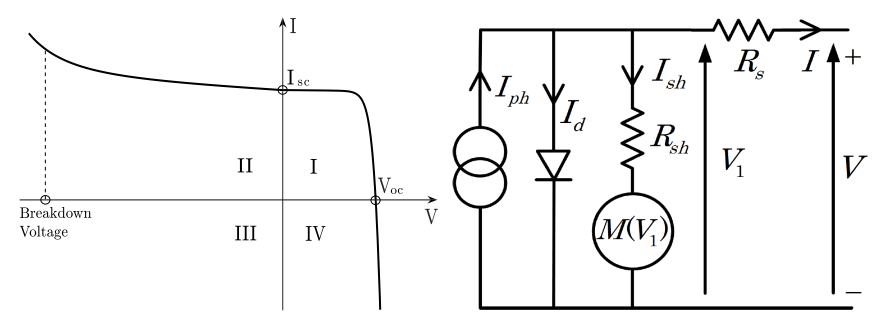

(a) I-V characteristic curve

(b) Equivalent circuit

Fig. 1: Bishop's model [19]

The transcendental equation of the equivalent circuit is provided by (1).

$$
\begin{aligned}
I= & I_{p h}-I_{0} \cdot\left[\exp \left(\frac{V+R_{s} \cdot I}{V_{t}}\right)-1\right] \\
& -\frac{V+R_{s} \cdot I}{R_{s h}} \cdot\left[1+k \cdot\left(1-\frac{V+R_{s} \cdot I}{V_{b}}\right)^{-n}\right]
\end{aligned}
$$

The eight parameters of (1) at standard test conditions (STC) of an irradiance of $1000 \mathrm{~W} / \mathrm{m}^{2}$ and a temperature of $25{ }^{\circ} C$, are presented in Table I. Given the fact that the $I$ $V$ characteristic equation is a transcendental one, a numerical solution is required. For this purpose, the Newton-Raphson algorithm was used.

TABLE I: PV cell characteristics [19]

\begin{tabular}{lccc}
\hline \hline Parameter & Symbol & Value & Unit \\
\hline \hline Photo current & $I_{p h}$ & 4.838 & $A$ \\
Reverse diode saturation current & $I_{o}$ & $10^{-7}$ & $A$ \\
Thermal voltage & $V_{t}$ & 0.0257 & $V$ \\
Series resistance & $R_{s}$ & 0.005 & $\Omega$ \\
Shunt resitance & $R_{s h}$ & 9 & $\Omega$ \\
Bishop's coefficient & $k$ & 0.1 & - \\
Bishop's coefficient & $n$ & 3.4 & - \\
Breakdown voltage & $V_{b}$ & -30 & $V$ \\
\hline \hline
\end{tabular}

\section{B. PV Array}

Having solved the characteristic $I-V$ equation, the last remaining step in order to complete the modeling of the PV array, is the connection of several elements together. Multiple cells are connected in series to form a PV module. PV modules are also connected in series forming a PV string which when connected in parallel create a PV array. The design of the PV array is completed with the use of blocking and bypass diodes as protective elements against the flow of inverse currents and inverse polarization respectively. The full specifications of the PV array are given in Table II.

\section{PV System}

As mentioned in the Introduction, in this study, a two-stage conversion topology, through the use of a boost converter and an inverter, was selected to connect the PV array to the grid 
TABLE II: PV array specifications

\begin{tabular}{lccc}
\hline \hline Parameter & Symbol & Value & Unit \\
\hline \hline Number of cells per module & $N_{c e l l}$ & 72 & - \\
Number of modules per string & $N_{\text {mod }}$ & 10 & - \\
Number of strings & $N_{s t r}$ & 30 & - \\
Number of bypass diodes per module & $N_{b p d}$ & 4 & - \\
Short circuit current & $I_{s c}$ & 145.3 & $A$ \\
Open circuit voltage & $V_{o c}$ & 407.67 & $V$ \\
Output power & $P_{p v}$ & 43.2 & $k W$ \\
\hline \hline
\end{tabular}

as shown in Fig. 2. The inverter to grid connection is a three phase one. Grid specifications are presented in Table III.

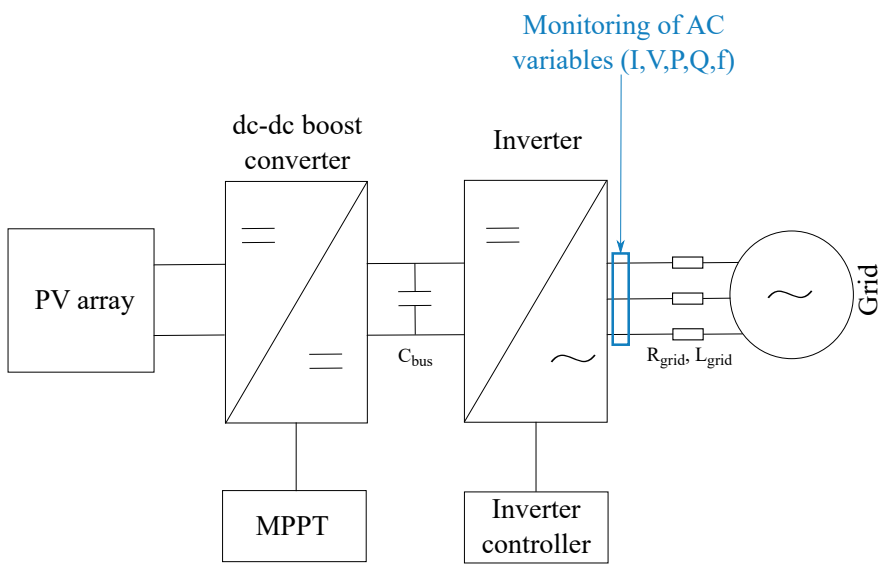

Fig. 2: PV system schematic

TABLE III: PV system and grid specifications

\begin{tabular}{lccc}
\hline \hline Parameter & Symbol & Value & Unit \\
\hline \hline Dc bus capacitance & $C_{\text {bus }}$ & 0.6 & $m F$ \\
Dc bus voltage & $V_{\text {bus }}$ & 800 & $V$ \\
Grid inductance & $L_{\text {grid }}$ & 5 & $m H$ \\
Grid resistance & $R_{\text {grid }}$ & 5 & $m \Omega$ \\
Grid frequency & $f_{\text {grid }}$ & 50 & $H z$ \\
Grid voltage & $V_{L L_{\text {gridrms }}}$ & 400 & $V$ \\
\hline \hline
\end{tabular}

\section{FAULT DETECTION AND LOCALIZATION}

Faults in a PV plant can be divided in two major categories: a) faults on the dc side of the plant and b) faults on the ac side. The occurrence of a fault is generally divided in three periods of time: the sub-transient, the transient and the steady-state. For the ac faults specifically, the sub-transient period is defined as the first cycle after the fault occurrence and the transient period as the next five to ten cycles [20]. An example is given in Fig. 3 where the SC fault between two phases and the ground is presented. The fault appears at $t_{0}=1 \mathrm{~s}$. The subtransient period of the fault begins with the fault occurrence at $t_{0}$ and lasts until $t_{1}$ with a duration of one cycle $(T=1 / f=$ $1 / 50=20 \mathrm{~ms}$ ). The transient period begins at $t_{1}$ and lasts until $t_{2}$-in this case $140 \mathrm{~ms}$ - where the fault current stabilizes in a final steady state. As it has already been mentioned in the Introduction, the developed method in this study creates an alarm signal in less than $60 \mathrm{~ms}$ from the fault occurrence, in the worst case scenario and as fast as $0.01 \mathrm{~ms}$ in the best case scenario, as it will be later explained, thus detecting the fault during its transient period.

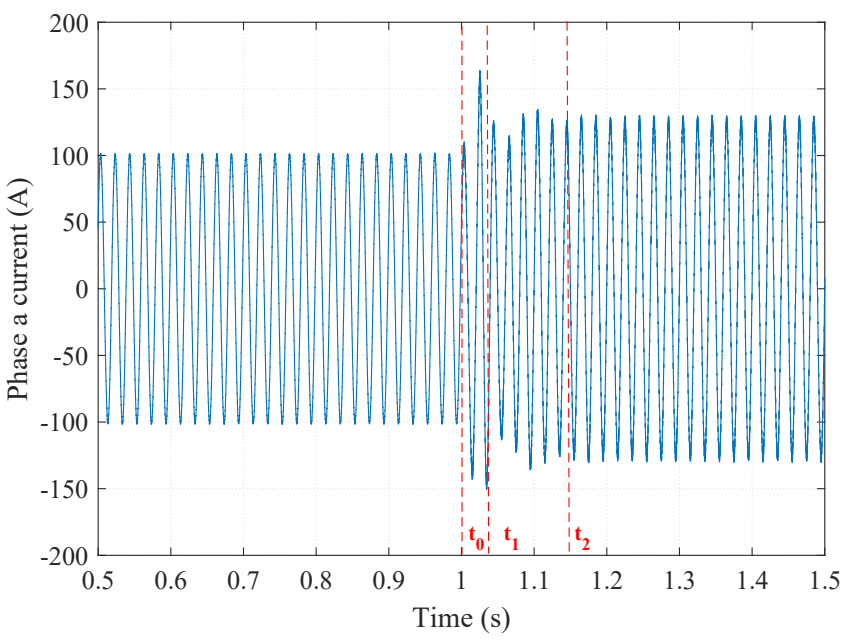

Fig. 3: Evolution over time of SC fault between phases a,b and the ground

\section{A. Fault Types}

A complete list of the studied faults is provided below:

a) faults inside the PV array:

[f01] shading of a number of PV modules

[f02] inverse bypass diode

[f03] short-circuited bypass diode

[f04] bypass diode breakdown

b) faults between the dc bus and the ground:

[f05] SC between the positive pole and the ground

[f06] $\mathrm{SC}$ between the negative pole and the ground

c) faults in the power electronics devices:

[f07] open-circuited converter IGBT

[f08] short-circuited converter IGBT

[f09] open-circuited inverter IGBT (1 IGBT in $1 \mathrm{leg}$ )

[f10] open-circuited inverter IGBTs (all IGBTs in $1 \mathrm{leg}$ )

[f11] short-circuited inverter IGBT (1 IGBT in $1 \mathrm{leg}$ )

[f12] short-circuited inverter IGBTs (all IGBTs in $1 \mathrm{leg}$ )

d) faults in the grid:

[f13] SC between one phase and the ground

[f14] SC between two phases and the ground

[f15] SC between three phases and the ground

[f16] SC between two phases

[f17] SC between three phases

[f18] voltage sag in one phase

[f19] voltage sag in two phases

[f20] voltage sag in three phases

More specifically, in the shading fault case (f01), $50 \%$ of the surface of the first five modules in the first twenty out of a total of thirty strings was covered by shade which was simulated by a reduction in half of their photocurrent. Moreover, in the 
bypass diode breakdown case (f04), the diode was replaced by a resistance of $5 \Omega$. Furthermore, in all SC faults, the fault resistance was set to $1 \Omega$. Finally, voltage sags (f18-f20) were simulated as a $50 \%$ sharp decrease of the initial voltage.

\section{B. Fault Detection}

The main objective of this study is to determine which type of fault is occurring, through the monitoring of electrical variables at the output of the inverter (ac side) as shown in Fig. 2. Through the three phase measurements of current $(I)$ and voltage $(V)$, the active $(P)$ and reactive $(Q)$ power were calculated. In order to complete the set of the monitored electrical variables, a phase locked loop (PLL) was used to obtain the frequency $(f)$ from the measured voltage.

The values of the monitored variables during normal operation of the system were compared to the values of the variables of faulty operation. A difference between the two suggested the existence of a fault under the condition that the irrandiance has not changed. It was observed that the current, the active and the reactive power were all altered in each fault case. Since the active power was affected in each and every fault case, a difference between the expected active power output of the power plant - based on weather conditions (irradiance level and temperature) - and the one attained at every moment, can be used as a first indicator of fault occurrence. The measurement of the irradiance level is achieved with the use of a calibrated PV reference device as described in [21]. However, in order for a fault to be identified, a dedicated combination of alterations in all of the variables is necessary. But, for the majority of faults a change in all the associated electrical variables is noticed. From this last observation arose the need to further specify the detection threshold settings and inspect in what way each variable was affected so as to narrow down the list of undetectable faults as much as possible.

\section{Fault Localization}

More detailed criteria around the current and the voltage were developed in order to generate a list of symptoms and construct the fault signature table. A first set of criteria included comparisons between faulty (FO) and normal (NO) operation values of voltage and current (i.e. $\left.\Delta I=I_{F O}-I_{N O}\right)$ and conclusions were drawn based on whether $\Delta I$ was negative or positive (s1) or $V_{F O}$ was equal to zero (s3). Another aspect of changes in $I$ and $\Delta V$ was whether they appeared symmetrically in all three phases or not (s2, s4). Furthermore, the sum of all three phase currents being equal to zero is considered as an extra symptom (s5). In addition, the method of symmetrical components was used to further analyze the measured voltage. Based on the magnitude and phase alterations of the voltage, the rest of the symptoms were created; s6 and s7-s9 respectively. A list summarizing all those symptoms is presented below:

[s1] current increase $\Delta I>0$ or current decrease $\Delta I<0$

[s2] in how many of the three phases is $I_{F O}=0$

[s3] voltage is equal to zero, $V_{F O}=0$ [s4] in how many of the three phases is $\Delta V<0$

[s5] the sum of phase currents is equal to zero

[s6] both the negative and the zero components exist

[s7] phase of the positive component, $\phi_{\text {pos }}<-25$

[s8] phase of the negative component, $\phi_{\text {neg }}<-110,-110<$ $\phi_{n e g}<-20$ or $-20<\phi_{n e g}<20$

[s9] phase of the zero component, $\phi_{0}>110, \phi_{0}>0$, $-110<\phi_{0}<110$ or $\phi_{0}<-110$

These symptoms along with the studied fault cases, were used to construct the fault signature table, Table IV. In the fault signature table, the symbol " $\sqrt{ }$ " is used to verify that the criteria described in the associated symptom were met while " $\mathrm{x}$ " marks the opposite. The symbol " $"$ is used as indicator that the specific symptom was of no interest to the associated fault. Another set of symbols was necessary to describe the changes in the current in s1; " + " is used when $\Delta I>0$ and "-" when $\Delta I<0$ while "+-" indicates that $\Delta I \lessgtr 0$ (current different from a direct system). For s2 and s4 the numbers " $0-3$ " indicate how many of the three phases are affected; " 0 " is for none of the phases, " 1 " for one phase etc. Moreover, for s8 the symbols " - - , "-" and "+-" appear when $\phi_{n e g}<-110,-110<\phi_{n e g}<-20$ and $-20<\phi_{n e g}<20$ respectively. Finally, for s9 where four conditions apply, " ++ " is used to indicate that $\phi_{0}>110$, "+" for $\phi_{0}>0$, "+-" for $-110<\phi_{0}<110$ and "-" for $\phi_{0}<-110$.

From the fault signature table, Table IV, sixteen faults or group of faults can be localized out of the total of twenty different faults. All faults inside the PV array (f01-f04), constitute altogether a group of faults that present exactly the same fault signature, making them impossible to discriminate from each other. This can be easily explained since the measurement point was located far from the source of the fault and by the time the signal reached the sensors, it had already been altered by the intermediary elements. The second and last group of inseparable faults are the faults inside the boost converter (f06, f07) since they too have the same fault signature. All the other faults can be detected and localized. In the cases of f10, $\mathrm{f} 11, \mathrm{f} 13$ and $\mathrm{f} 14$, the faulty phase was also detected through monitoring of the current and voltage behavior.

\section{FAULT DIAGNOSIS METHOD}

\section{A. Fault Diagnosis Strategy}

As discussed in the previous Section, a difference between the expected value of the PV power plant's active power output and the measured one -according to current irradiance and temperature measurements- was the first indicator of a fault occurrence. From this point, an algorithm was developed in order to localize each fault or group of faults. In Fig. 4, a flowchart with all the decision levels of the proposed algorithm is presented. When a fault is identified, the algorithm is terminated. 
TABLE IV: Fault signature table

\begin{tabular}{|c|c|c|c|c|c|c|c|c|c|}
\hline & \multicolumn{9}{|c|}{ Symptoms } \\
\hline Faults & $s 1$ & $s 2$ & $s 3$ & $s 4$ & $s 5$ & $s 6$ & $s 7$ & $s 8$ & $s 9$ \\
\hline f01 & - & 0 & $\mathrm{x}$ & 0 & $\sqrt{ }$ & 1 & 1 & I & 1 \\
\hline f02 & - & 0 & $\mathrm{x}$ & 0 & $\sqrt{ }$ & I & l & I & I \\
\hline f03 & - & 0 & $\mathrm{x}$ & 0 & $\sqrt{ }$ & I & 1 & I & I \\
\hline f04 & - & 0 & $\mathrm{x}$ & 0 & $\sqrt{ }$ & I & 1 & I & I \\
\hline f05 & - & 0 & $\sqrt{ }$ & 3 & - & 1 & 1 & 1 & 1 \\
\hline f06 & - & 0 & $\sqrt{ }$ & 3 & + & 1 & 1 & 1 & 1 \\
\hline f07 & - & 3 & $\mathrm{x}$ & 3 & $\sqrt{ }$ & 1 & 1 & 1 & 1 \\
\hline f08 & - & 3 & $\mathrm{x}$ & 3 & $\sqrt{ }$ & I & l & I & I \\
\hline f09 & +- & 0 & $\mathrm{x}$ & 0 & $\sqrt{ }$ & 1 & 1 & I & 1 \\
\hline f10 & +- & 1 & $\mathrm{x}$ & 1 & $\sqrt{ }$ & 1 & 1 & 1 & 1 \\
\hline f11 & +- & 0 & $\mathrm{x}$ & 3 & $\sqrt{ }$ & I & I & 1 & I \\
\hline f12 & +- & 0 & $\sqrt{ }$ & 3 & $\sqrt{ }$ & I & I & I & I \\
\hline f14 & + & 0 & $\mathrm{x}$ & 2 & $\sqrt{ }$ & $\sqrt{ }$ & 1 & 1 & 1 \\
\hline f13 & + & 0 & $\mathrm{x}$ & 1 & $\sqrt{ }$ & $\sqrt{ }$ & 1 & -- & 1 \\
\hline f18 & + & 0 & $\mathrm{X}$ & 0,1 & $\sqrt{ }$ & $\sqrt{ }$ & $\mathrm{x}$ & 1 & +- \\
\hline f19 & + & 0 & $\mathrm{x}$ & 0 & $\sqrt{ }$ & $\sqrt{ }$ & $\mathrm{x}$ & $T$ & ++ \\
\hline f15 & + & 0 & $\mathrm{X}$ & 0 & $\sqrt{ }$ & $\mathrm{X}$ & $\sqrt{ }$ & +- & - \\
\hline f17 & + & 0 & $\mathrm{x}$ & 0 & $\sqrt{ }$ & $\mathrm{x}$ & $\sqrt{ }$ & +- & + \\
\hline $\mathbf{f 2 0}$ & + & 0 & $\mathrm{X}$ & 0 & $\sqrt{ }$ & $\mathrm{x}$ & $\mathrm{x}$ & +- & +- \\
\hline f16 & + & 0 & $\mathrm{x}$ & 0 & $\sqrt{ }$ & $\mathrm{x}$ & $\mathrm{x}$ & - & - \\
\hline
\end{tabular}

\section{B. Threshold Crossing Settings}

In order to implement the diagnostic strategy presented in Fig. 4 into a MATLAB/Simulink file, further specification of the threshold crossing settings was deemed necessary. The configuration of the implemented threshold crossing settings was made in order for them to be compliant with the various levels of irradiation. Following the logic of the algorithm's flowchart, the threshold settings are presented below. In order to check if the sum of the three phase currents was equal to zero (s5), their instantaneous values were added and the result should have been equal to zero with an error of $1 A:-1 A<\operatorname{sum}\left(i_{a}, i_{b}, i_{c}\right)<1 A$. The $1 A$ threshold criterion around zero was chosen since it corresponds at $1 \%$ of the peak value of the current at normal operation and STC $\left(I_{\text {peak }}\right.$ O $\left._{S T C}\right)$.

Continuing with s3 and s2, where the voltage and current, respectively, were supposed to be equal to zero, the thresholds were again set at $1 \%$ of the peak value of the current and voltage at normal operation and STC $\left(-1 A<I_{F O}<\right.$ $1 \mathrm{~A}$ or $-5.53 \mathrm{~V}<V_{F O}<5.53 \mathrm{~V}$ ) but this time the root mean square (RMS) values of the measured current and voltage were used for accuracy reasons.

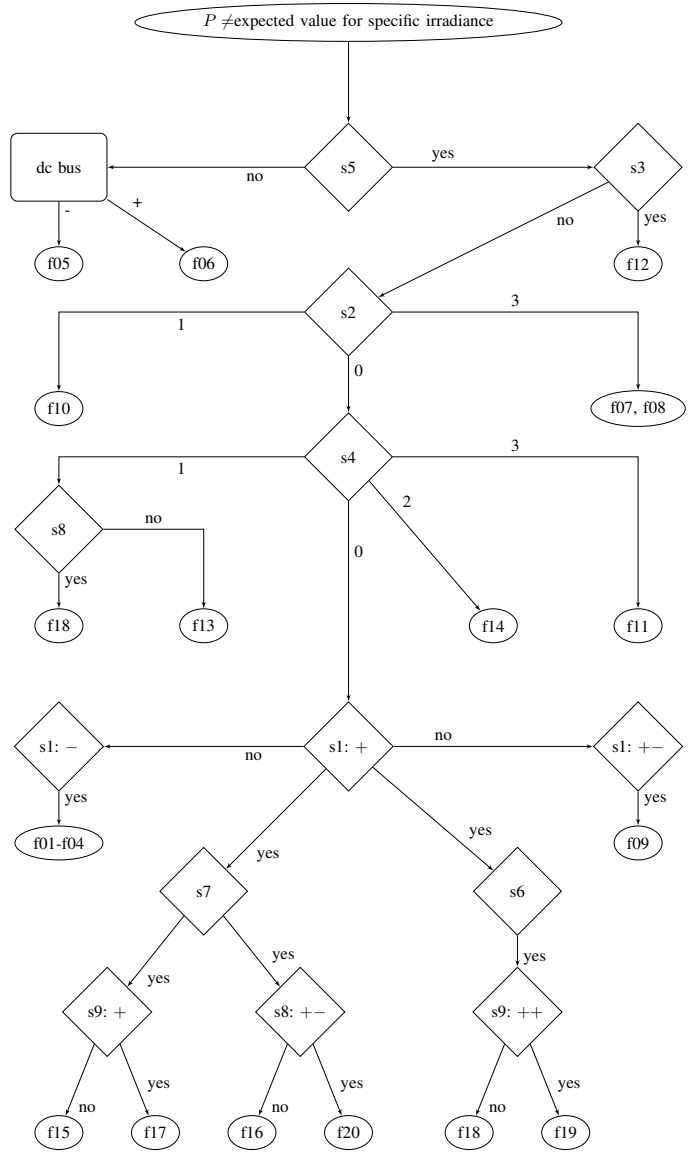

Fig. 4: Flowchart

Moving on to the current and voltage differences between faulty and normal operation, $\Delta I$ and $\Delta V$, which were used in symptoms $\mathrm{s} 1$ and $\mathrm{s} 4$, their moving maximum was traced with a sliding window of $40 \mathrm{~ms}: \Delta I=\operatorname{moving}_{\max }\left(I_{F O}\right)-$ moving $_{\max }\left(I_{N O}\right)$. The choice of a sliding window of $40 \mathrm{~ms}$ -time equal to twice the period of the signal $(20 \mathrm{~ms})$ - was made in order to constantly capture the maximum values of the sinusoidal current and voltage signals when imported into the diagnosis system. The $\Delta V$ being negative was defined as $\Delta V<-5.53 \mathrm{~V}$, again selected because it corresponds at $1 \%$ of $V_{\text {peak }}$ O $_{S T C}$. At the same time, the threshold crossing setting for $\Delta I$ was set around $2 A: \Delta I>2 A$ and $\Delta I<-2 A$ corresponding at $2 \%$ of $I_{\text {peak }}$ NO $_{S T C}$. The $2 \%$ threshold was chosen here to avoid false alarms at low irradiances.

Regarding the symmetrical component analysis, their moving average was traced, once more over a sliding window of $40 \mathrm{~ms}$. The existence of the negative and the zero sequence components was verified by checking whether or not they were different from zero; the threshold for this case was set at $5.53 \mathrm{~V}$ around zero for consistency reasons. For the rest of the symptoms (s7 to s9) the implemented threshold settings were the ones described in Section III. 


\section{Method Validation}

The developed diagnosis method was validated by simulations means for different irradiance levels and more specifically for $1000,800,600,400$ and $200 \mathrm{~W} / \mathrm{m}^{2}$. The required time for the method to create the alarm signal for the different irradiance levels and faults was monitored. The maximum and minimum diagnosis time for each fault or group of faults were also recorded. The method can detect and localize a fault in some cases as fast as $0.01 \mathrm{~ms}$ after the fault occurrence and in general in less than $60 \mathrm{~ms}$. An exception to that is the faulty phase detection for the one short-circuited IGBT inside the inverter fault (f11), where an extra latency of $30 \mathrm{~ms}$-linked to reaction of the inverter controller- was observed after the detection of the fault itself.

\section{CONCLUSIONS AND FUTURE WORKS}

\section{A. Conclusions}

The purpose of the current study was to develop, through a signal approach, a fault diagnosis method for GCPV systems capable of detecting and localizing faults on both dc and ac side based on current and voltage measurements at the output of the inverter. Due to the vast amount of possible faults, only twenty common faults were considered in this study. While all faults are detectable, fourteen individual fault cases and two groups of faults (faults inside the PV and faults inside the boost converter) were localized out of a total of twenty studied fault cases. Faults inside the PV and inside the boost converter, were too far away from the sensor's measurement point for the signal to remain unaffected by the intermediary elements. As a result, they could only be localized as groups of faults.

Assuming that only one fault is occurring at a time, the method creates an alarm signal in less than $60 \mathrm{~ms}$. Finally, the robustness of the method was validated via simulations for various irradiance levels ranging from STC to $200 \mathrm{~W} / \mathrm{m}^{2}$.

\section{B. Future Works}

Further work is required to expand the list of studied faults. Moreover, the robustness of the algorithm could be tested for temperature and grid voltage variations over time; error in measurements could be also taken into account. Finally, the last step would be to experimentally validate the method by obtaining real time measurements of an GCPV.

\section{REFERENCES}

[1] "IEA-PVPS Trends 2017 in Photovoltaic Applications," Tech. Rep. IEA PVPS T1-32:2017. [Online]. Available: http://www.iea-pvps.org/fileadmin/dam/public/report/statistics/ IEA-PVPS_Trends_2017_in_Photovoltaic_Applications.pdf

[2] J. E. Quiroz, J. S. Stein, C. K. Carmignani, and K. Gillispie, "In-situ module-level I-V tracers for novel PV monitoring," in 2015 IEEE 42nd Photovoltaic Specialist Conference (PVSC), Jun. 2015, pp. 1-6.

[3] M. Miwa, S. Yamanaka, H. Kawamura, H. Ohno, and H. Kawamura, "Diagnosis of a Power Output Lowering of PV Array with a (-dI/dV)V Characteristic," in 2006 IEEE 4th World Conference on Photovoltaic Energy Conference, vol. 2, May 2006, pp. 2442-2445.
[4] A. Chouder and S. Silvestre, "Automatic supervision and fault detection of PV systems based on power losses analysis," Energy Conversion and Management, vol. 51, no. 10, pp. 1929-1937, Oct. 2010. [Online]. Available: http://linkinghub.elsevier.com/retrieve/pii/ S0196890410000919

[5] T. Shimakage, K. Nishioka, H. Yamane, M. Nagura, and M. Kudo, "Development of fault detection system in PV system," in 2011 IEEE 33rd International Telecommunications Energy Conference (INEC), Oct. 2011, pp. 1-5.

[6] R. Platon, J. Martel, N. Woodruff, and T. Y. Chau, "Online Fault Detection in PV Systems," IEEE Transactions on Sustainable Energy, vol. 6, no. 4, pp. 1200-1207, Oct. 2015.

[7] W. Chine, A. Mellit, A. M. Pavan, and S. Kalogirou, "Fault detection method for grid-connected photovoltaic plants," Renewable Energy, vol. 66, pp. 99-110, Jun. 2014. [Online]. Available: http://linkinghub.elsevier.com/retrieve/pii/S0960148113006617

[8] M. Dhimish, V. Holmes, and M. Dales, "Parallel fault detection algorithm for grid-connected photovoltaic plants," Renewable Energy, vol. 113, no. Supplement C, pp. 94-111, Dec. 2017. [Online]. Available: http://www.sciencedirect.com/science/article/pii/S0960148117304780

[9] E. Garoudja, F. Harrou, Y. Sun, K. Kara, A. Chouder, and S. Silvestre, "Statistical fault detection in photovoltaic systems," Solar Energy, vol. 150, pp. 485-499, Jul. 2017. [Online]. Available: http://linkinghub.elsevier.com/retrieve/pii/S0038092X17303377

[10] Y. Zhao, L. Yang, B. Lehman, J. F. d. Palma, J. Mosesian, and R. Lyons, "Decision tree-based fault detection and classification in solar photovoltaic arrays," in 2012 Twenty-Seventh Annual IEEE Applied Power Electronics Conference and Exposition (APEC), Feb. 2012, pp. 93-99.

[11] C. B. Jones, J. S. Stein, S. Gonzalez, and B. H. King, "Photovoltaic system fault detection and diagnostics using Laterally Primed Adaptive Resonance Theory neural network," in 2015 IEEE 42nd Photovoltaic Specialist Conference (PVSC), Jun. 2015, pp. 1-6.

[12] P. Ducange, M. Fazzolari, B. Lazzerini, and F. Marcelloni, "An intelligent system for detecting faults in photovoltaic fields," in 2011 11th International Conference on Intelligent Systems Design and Applications, Nov. 2011, pp. 1341-1346.

[13] A. Drews, A. de Keizer, H. Beyer, E. Lorenz, J. Betcke, W. van Sark, W. Heydenreich, E. Wiemken, S. Stettler, P. Toggweiler, S. Bofinger, M. Schneider, G. Heilscher, and D. Heinemann, "Monitoring and remote failure detection of grid-connected PV systems based on satellite observations," Solar Energy, vol. 81, no. 4, pp. 548-564, Apr. 2007. [Online]. Available: http://linkinghub.elsevier.com/retrieve/ pii/S0038092X06002040

[14] T. Takashima, J. Yamaguchi, and M. Ishida, "Fault detection by signal response in PV module strings," in 2008 33rd IEEE Photovoltaic Specialists Conference, May 2008, pp. 1-5.

[15] M. Gonzlez, B. Raison, S. Bacha, and L. Bun, "Fault diagnosis in a grid-connected photovoltaic system by applying a signal approach," in IECON 2011 - 37th Annual Conference of the IEEE Industrial Electronics Society, Nov. 2011, pp. 1354-1359.

[16] I. S. Kim, "Fault detection algorithm of the photovoltaic system using wavelet transform," in India International Conference on Power Electronics 2010 (IICPE2010), Jan. 2011, pp. 1-6.

[17] W. De Soto, S. A. Klein, and W. A. Beckman, "Improvement and validation of a model for photovoltaic array performance," Solar Energy, vol. 80, no. 1, pp. 78-88, Jan. 2006. [Online]. Available: //www.sciencedirect.com/science/article/pii/S0038092X05002410

[18] D. Picault, B. Raison, S. Bacha, J. de la Casa, and J. Aguilera, "Forecasting photovoltaic array power production subject to mismatch losses," Solar Energy, vol. 84, no. 7, pp. 1301-1309, 2010. [Online]. Available: http://www.sciencedirect.com/science/article/pii/S0038092X10001556

[19] L. Bun, "Détection et localisation de défauts pour un systéme PV," PhD Thesis, Université Grenoble Alpes, Nov. 2011. [Online]. Available: https://tel.archives-ouvertes.fr/tel-00647189/document

[20] M. E. Baran and I. El-Markaby, "Fault analysis on distribution feeders with distributed generators," IEEE Transactions on Power Systems, vol. 20, no. 4, pp. 1757-1764, Nov. 2005.

[21] L. Dunn, M. Gostein, and K. Emery, "Comparison of pyranometers vs. PV reference cells for evaluation of PV array performance," in 2012 38th IEEE Photovoltaic Specialists Conference, Jun. 2012, pp. 002899 002904. 